\title{
Cultural dimensions of sacred forests in the Western Ghats Biodiversity Hot Spot, Southern India and its implications for biodiversity protection
}

\author{
Ankur Patwardhan ${ }^{1,2}$ (D) Pooja Ghate ${ }^{2} \cdot$ Monali Mhaskar ${ }^{1,2} \cdot$ Amit Bansude $^{1,2}$
}

Received: 16 July 2020 / Accepted: 17 August 2021 / Published online: 29 September 2021

(c) The Author(s) 2021

\begin{abstract}
Sacred groves are relict forests dedicated to local deities that have been informally protected and managed by local communities over centuries. To gain greater insights into underlying sociocultural reasons for protection, and possibilities of strengthening such efforts, a study has been undertaken in 66 sacred groves in the Maharashtra State of Western Ghats biodiversity hot-spot in India, which shows different facets of human-nature relationships. Primary data on size, ownership, deity, religious aspects and awareness amongst the local people was collected through site visits, semi-structured interviews, and by participating in village meetings. It was observed that village councils owned $48 \%$ of the groves as against temple trusts $(41 \%)$ and forest department plus individually owned groves (11\%). Nearly $52 \%$ of the groves have an area less than one-half hectare. Forty-seven percent of the groves have male deities, $29 \%$ female deities and $26 \%$ were dedicated to spirits. Eighty percent of the local people were aware of cultural and religious aspects associated with the groves, whereas awareness about ecological and utilitarian values declined steeply to less than $20 \%$ of the population, necessitating the explanation of scientific conservation values of these critical ecosystems to the local people. The paper also discusses the significance of such studies in connection with the relevant UN Sustainable Development Goals and AICHI Biodiversity targets. In addition, it also discusses links with national biodiversity targets and how legal provisions under India's Biological Diversity Act (2002) can be used to benefit both the ecosystem and the cultural
\end{abstract}

Ankur Patwardhan

ankurpatwardhan@gmail.com

1 Annasaheb Kulkarni Department of Biodiversity, M.E.S. Abasaheb Garware College, Karve Road, Pune 411 004, Maharashtra, India

2 Research and Action in Natural Wealth Administration (RANWA), 16, Swastishree Society, Ganesh Nagar, Kothrud, Pune 411 052, Maharashtra, India 
values of the people, and how such informal institutions can be strengthened under formal protection mechanisms.

$\begin{array}{ll}\text { Abbreviations } \\ \text { SDGs } & \text { Sustainable Development Goals } \\ \text { ha } & \text { Hectare } \\ \text { ICCAs } & \text { Indigenous and Community Conserved Areas } \\ \text { NWG } & \text { Northern Western Ghats } \\ \text { Sq. km } & \text { Square Kilometers } \\ \text { m } & \text { Meter } \\ \text { MSL } & \text { Mean sea level } \\ \text { GPS } & \text { Global Positioning System } \\ \text { IUCN } & \text { International Union for Conservation of Nature } \\ \text { CDI } & \text { Cumulative Disturbance Index } \\ \text { MEA } & \text { Millennium Ecosystem Assessment } \\ \text { Ag } & \text { Agriculture } \\ \text { F } & \text { Forest } \\ \text { H } & \text { Horticulture } \\ \text { M } & \text { Male } \\ \text { F } & \text { Female } \\ \text { MoEF\&CC } & \text { Ministry of Environment, Forests \& Climate Change } \\ \text { BMC } & \text { Biodiversity Management Committee } \\ \text { CCA } & \text { Community Conserved Areas }\end{array}$

\section{Introduction}

The significance of sustainable development for the continued well-being of humans and ecosystems has been highlighted by many scholars. To achieve sustainable development for all, seventeen Sustainable Development Goals (SDGs) were adopted by all member states of the United Nations in 2015. ${ }^{1}$ Human and ecosystem well-being calls for protection, restoration, and implementation of sustainable management of all types of forests and ecosystems that provide important services related to food, health, and livelihood. The strategic goals of the AICHI Biodiversity Targets identified the enhancement of benefits to all from biodiversity and ecosystem services. ${ }^{2}$ Such enhancement requires active and effective use of traditional knowledge and the practices of indigenous and local communities relevant for conservation, and sustainable use of biodiversity. In this context, sacred forests represent a classic case of unique ecosystems that have been informally protected and managed by local communities over the course of centuries.

\footnotetext{
${ }^{1}$ This information is taken from the website: https://sustainabledevelopment.un.org/ and the access time was April 18, 2020.

${ }^{2}$ This information is taken from the Convention on Biodiversity Website: https://www.cbd.int/sp/targets/ and the access time was July 10, 2020.
} 
Sacred groves are relict forest patches that are dedicated to local deities (Gadgil and Vartak 1981) and are home to wildlife outside the formally protected areas. India is estimated to have over one hundred thousand such groves (Malhotra et al. 2000) scattered all over the country with size varying from less than 0.1 ha to 100 ha. They are also known to act as wildlife corridors, especially when found in continuum with the forest cover. They are informally protected and managed by local communities through customary laws and belief systems (Gadgil and Vartak 1975). They represent traditional ecological knowledge that balances use and protection of natural resources. It was believed that disturbing these forest patches would invite the wrath of the spirits to whom they are dedicated. Such sacred natural sites are also found elsewhere in the world (in thirty-three countries across the globe) in such forms as church forests in Ethiopia (Cardelus et al. 2017), sacred groves in Ghana (Nganso et al. 2012), and graveyard jungles in Turkey (Loki et al. 2015). The sacred groves of India are examples of Indigenous and Community Conserved Areas (ICCAs) that are consistent with ICCAs globally (Berkes 2009). These sacred groves are frequently managed under local systems of governance. A symbiotic relationship exists between species and cultural identity, for example, between blackbuck antelope (Antilope cervicarpa) and Bishnoi (people belonging to the Bishnoi Hindu sect) (Hall 2011), and ecosystems and nature worship as is found in relation to sacred ponds or bodies of water (Burman 1996; Chandran and Hughes 1997). A strong relationship also exists between habitats and cultural identity as found in particular communities that hold annual festivals in sacred places, such as the Santal people and their local places called santal-sthal or jaherthan, located along the edge of villages (Chakraborty 2019). A perennial stream or river originating in such sacred places has been found many times. Sometimes these sacred streams serve as the only source of water for the nearby villages. Often it has been observed that the local people collect wild edible plants (uncultivated foods), and non-timber forest products such as honey and fodder for cattle from these areas. Studies pertaining to exploration of such human-nature relationships provide insights into various facets ensuring sustainable human development which is natural-resource dependent have attained high significance. In this vein, pioneering and comprehensive documentation of sacred groves has been provided by Gadgil and Vartak $(1975,1976,1981)$.

Despite abundance of sacred groves in India, they are disappearing due to cultural changes and pressure to utilize the natural resources within the groves (Chandrakanth et al. 2004; Ormsby and Bhagwat 2010). Management and ownership of groves vary from state to state in India and there are different approaches even within states. These sites also play a key role in maintaining biological diversity in areas affected by land-use changes (Bhagwat et al. 2005). In the Western Ghats biodiversity hotspot (a hill range extending along the Western coast of India in Southern India), sacred groves are either in continuum with the forest areas or juxtaposed between human habitation and ever-increasing agricultural land. In such cases, they are surrounded by paddy fields or sugarcane cultivation. Therefore, these sacred groves are subject to the influence of farming practices such as seasonal burning and land clearing. In certain areas, these patches represent the sole remaining natural forests outside of protected areas and therefore, they are important for the conservation of biodiversity as well as the preservation of cultural histories (Acharya and 
Ormsby 2017). Such forest-agriculture landscapes and the protection of a functional biodiversity island in the form of sacred groves are representative examples of 'cultural landscape' produced by the interaction between these social and ecological drivers of landscape development (Bhagwat et al. 2013).

In the northern Western Ghats (NWG), sacred groves still exist variously in the landscape although the importance given to them is declining. Temples are being built for the gods but the tendency to dedicate the groves to the gods is decreasing. Given that more than half of the natural habitat in the NWG has been cleared (WWF 2007), it has become an absolute necessity to understand (i) how these informal protected areas are managed and conserved, (ii) the social norms and the code of conduct that the local communities follow to protect these areas, (iii) the degree of awareness these local communities possess, and (iv) current threats to these sacred forests. This paper investigates the above aspects in the proposed eco-sensitive zone in the Sahyadri-Konkan ecological corridor (CEPF 2007) and provides insights into how they can be managed in future.

\section{Materials and methods}

\section{Study area}

The study area lies in Sawantwadi Taluka (Township), in Sindhudurg District of Maharashtra (Fig. 1), situated in the Sahyadri-Konkan ecological corridor. The corridor covers an area of about 10,489 sq. km and further extends to Karnataka and Goa (CEPF 2007), part of Western Ghats. Sixty-six sacred groves from thirty-six villages across the proposed eco-sensitive zone of Sawantwadi Taluka were surveyed for the present study. ${ }^{3}$ These sacred groves are primarily situated at a low or mid-elevation gradient from 8 to $750 \mathrm{~m}$ above mean sea level (MSL) and exhibit evergreen to semi-evergreen forest types.

\section{Study design}

The current study is a part of an ongoing initiative documenting sacred natural sites in Sawantwadi Taluka, Sindhudurg District. Data collection primarily spanned over a period of one and a half years from December 2017 to June 2019.

The extent and status of sacred groves were studied at following different levels; (i) size, (ii) ownership, (iii) deity, (iv) cultural services offered, (v) customs and taboos, (vii) belief systems and (viii) awareness among the local people about various services provided by these groves. Surrounding land use was also recorded to understand the distribution of the sacred groves in the overall landscape, for instance, whether isolated and forming an "island of biodiversity," or juxtaposed

\footnotetext{
3 This information comes from The Gazette of India notification by Ministry of Environment, Forests and Climate Change. The website is: http://moef.gov.in/wp-content/uploads/2019/05/western-ghats.pdf and the access time was April 5, 2020.
} 


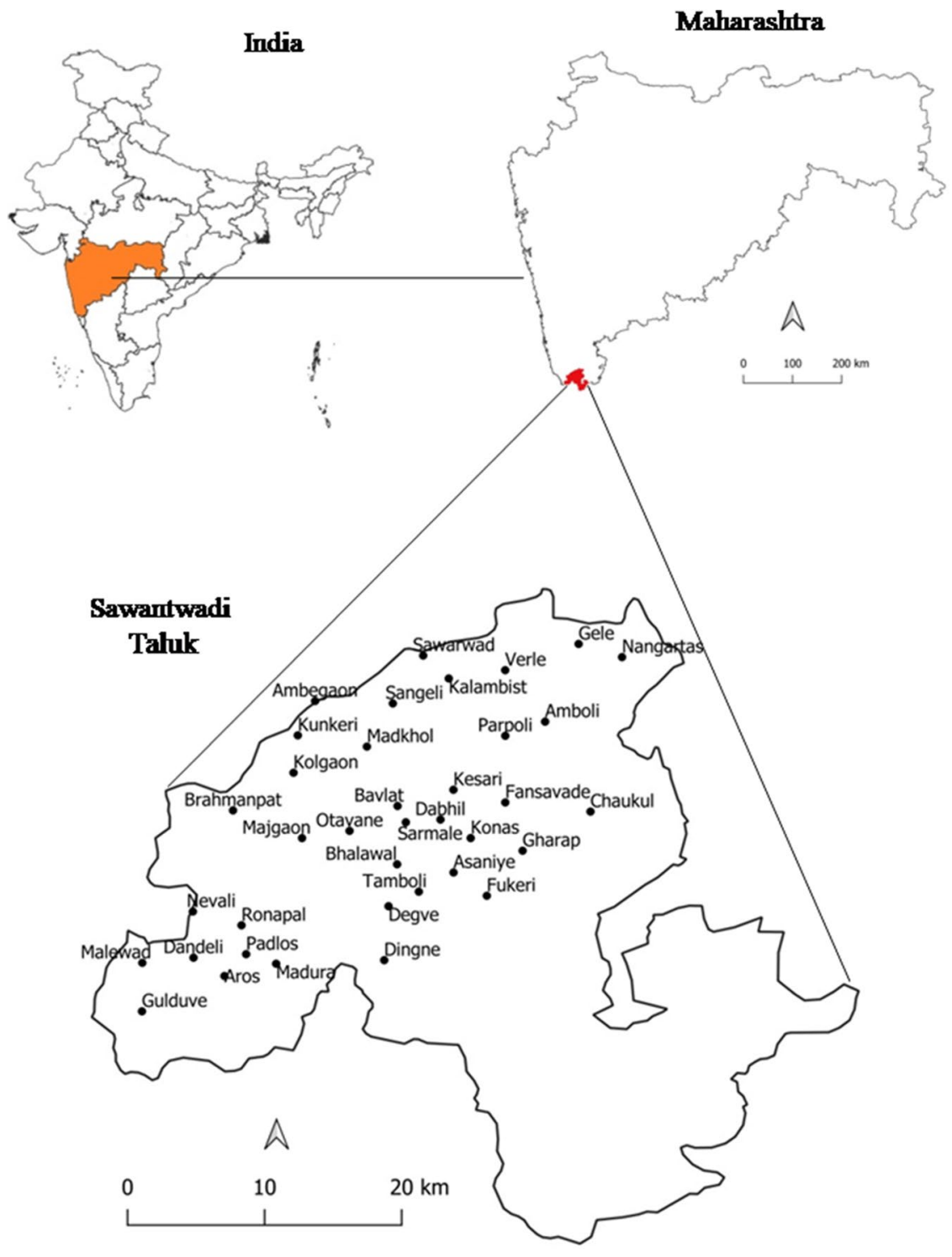

Fig. 1 Study Area

with the forest and habitation or agriculture. This also served as an indicator of anthropogenic pressure (if any) on the grove. The number of plant species observed in the sacred groves, along with the presence of species assessed by the International Union for Conservation of Nature (IUCN), and any disturbance experienced by the sacred grove have also been recorded. Data obtained from this is presented in Table 1. 







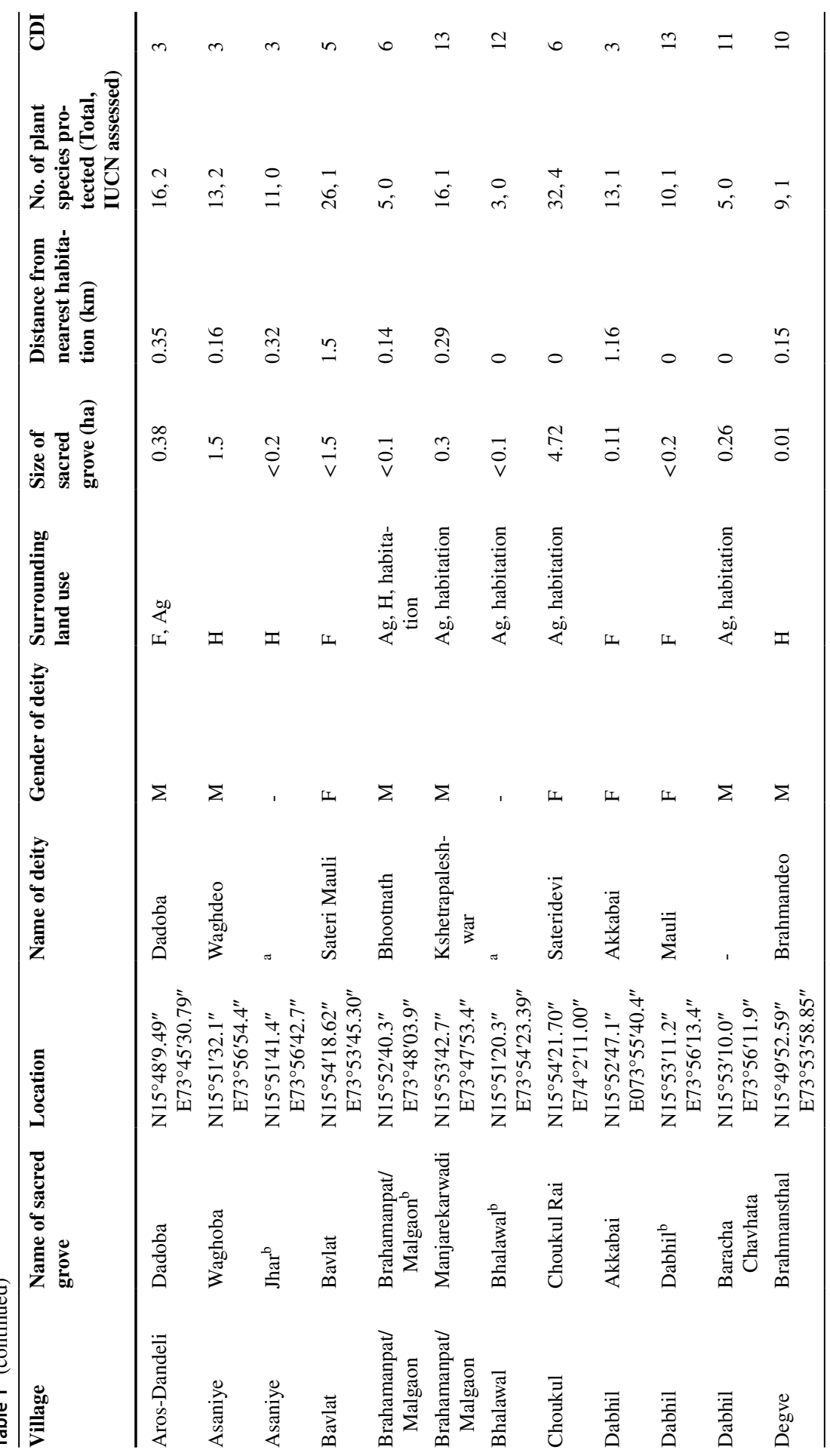




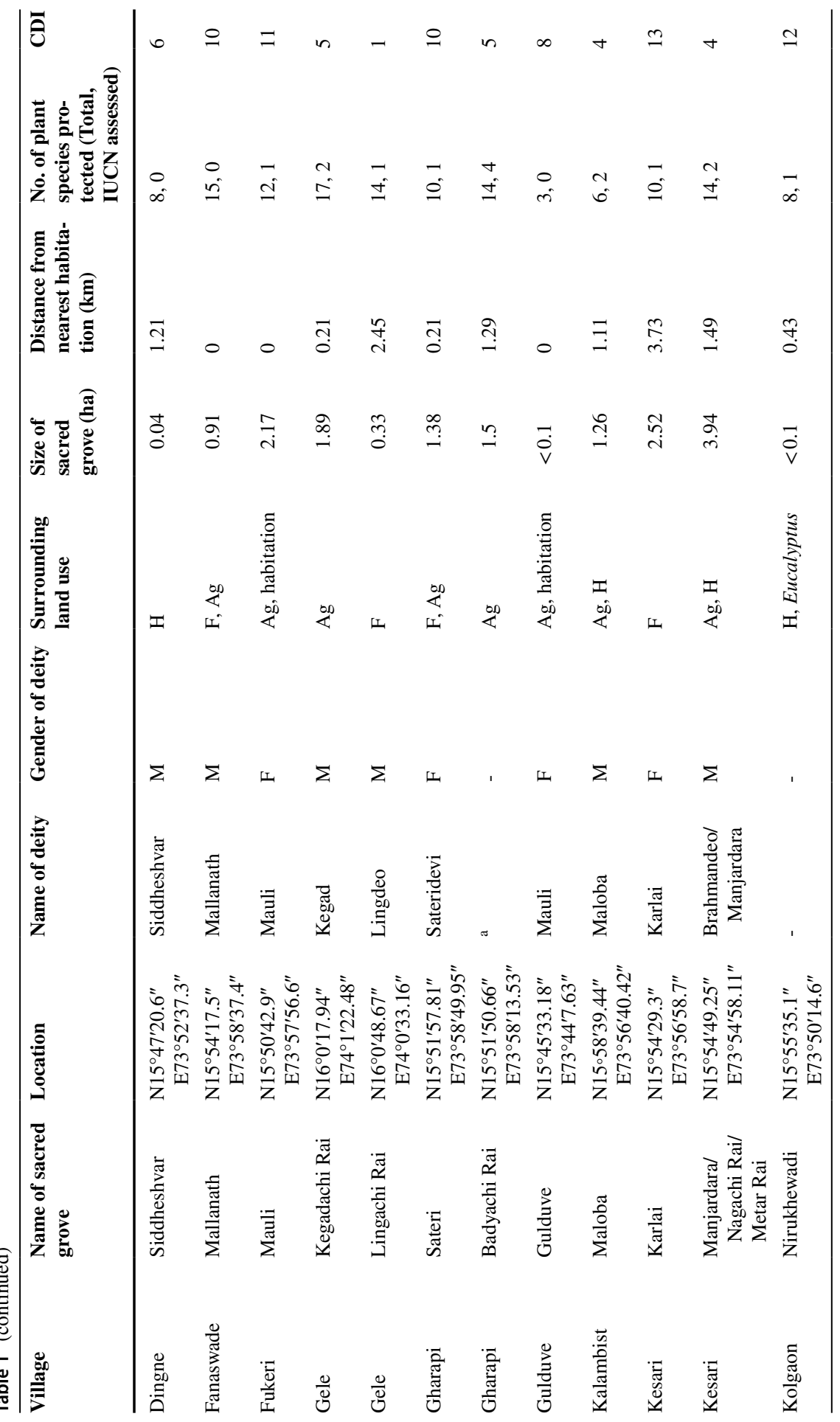




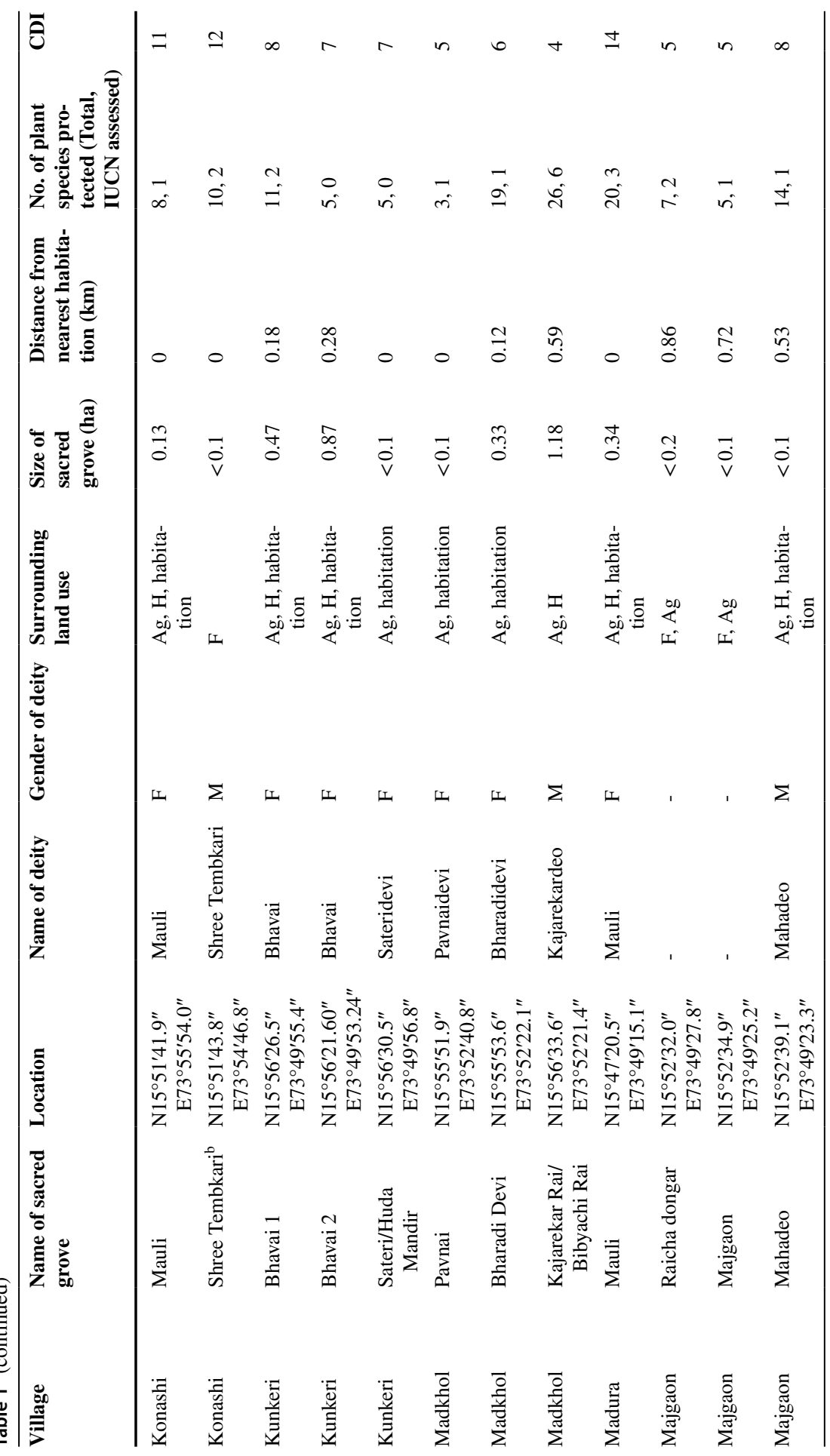




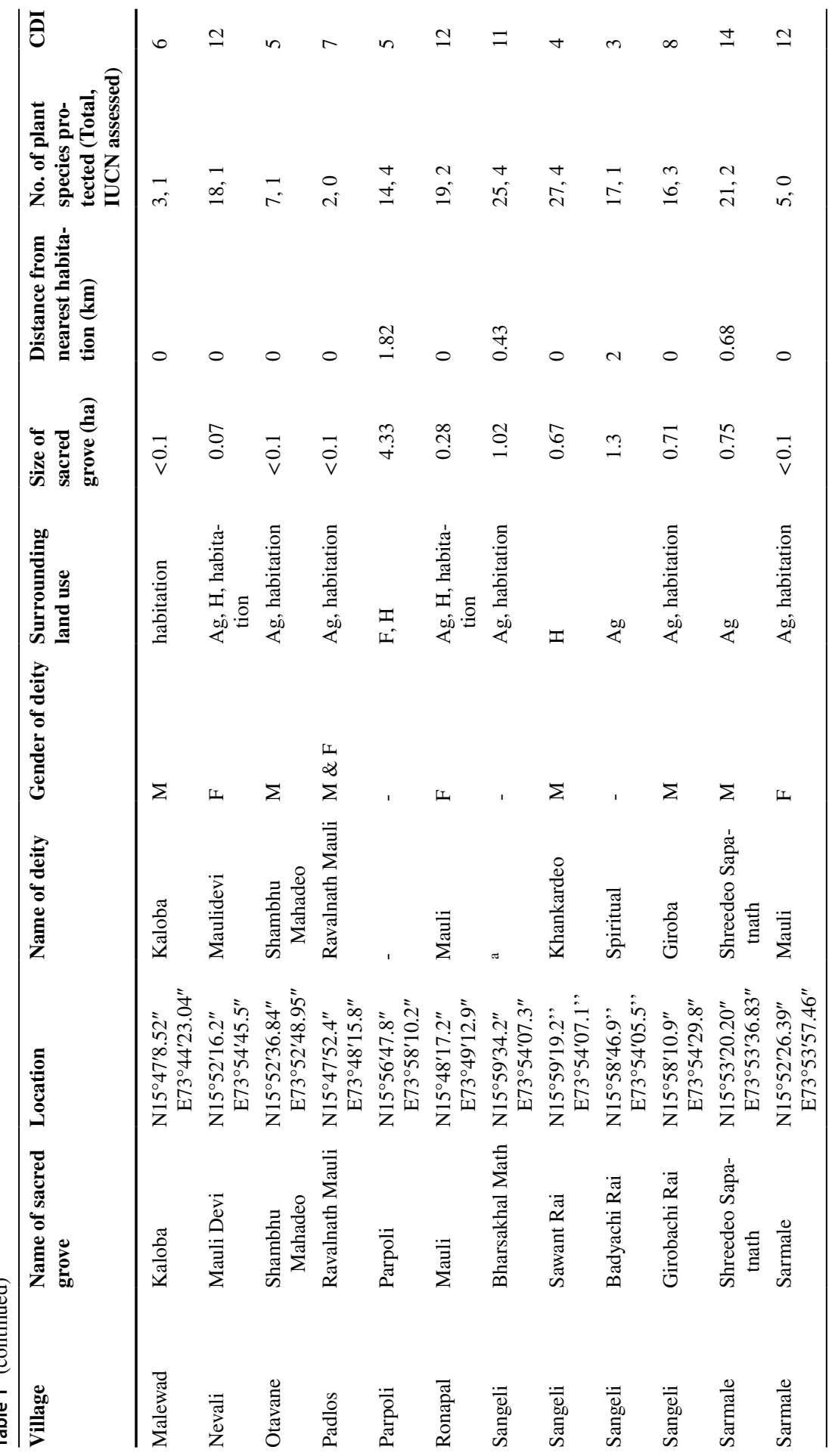




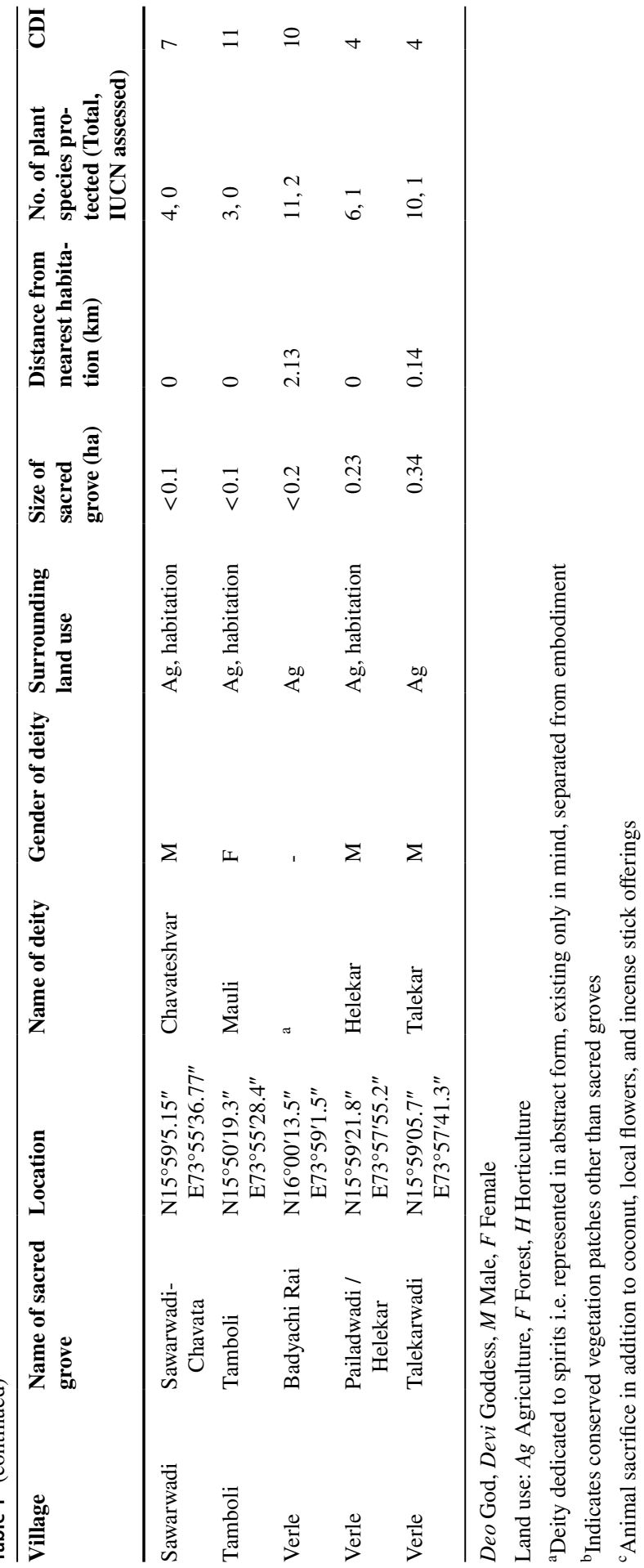




\section{Interviews}

Primary data on the sacred groves were collected through site visits, focused group discussions with local community members and priests, and by participating in village meetings. The semi-structured interview-based approach was adopted to collect information that includes ownership status, customs, rules and regulations, and traditions associated with the groves. Information about the watercourses originating or flowing from these groves was also noted. To understand the level of awareness about various dimensions of the groves, people were categorized into three age groups, viz. school children, youth, and elders, and further interviewed separately. Photo and audio documentation formed an integral component of the study.

\section{Boundary delineation}

The area of the groves was demarcated from the surrounding landscape by delimiting the boundaries with the help of a Global Positioning System (GPS) (Garmin Map $78 s$ ). GPS coordinates then were plotted to calculate the area of the sacred grove using the Earth Point website (earthpoint.us).

\section{Transect walks}

Encountered plant species were recorded using random transect walks. For the recording of plant-species richness, the checklist method of sampling was adopted. The IUCN (International Union for Conservation of Nature) Red List was referenced to assign status to the species. However, it should be noted that the species data provided here is not comprehensive, as the focus of the study was to comprehend socio-cultural dimensions and the species data is a mere indication of the potential of these informally protected areas in conserving local biodiversity. Intensive exploration adopting a systematic sampling approach would lead to more insights into various biodiversity elements.

\section{Disturbance assessment}

Each sacred grove was assessed for the intensity of human disturbance which it had suffered. For this, the methodology adopted by Tadwalkar et al. (2012) was followed and modified to suit the present study. Evidence for disturbance was based on observation of (1) grazing, (2) lopping, (3) fire, (4) weeds, (5) cut stumps, (6) soil removal, (7) exotic species, (8) paths/roads, (9) firewood collection and (10) garbage. For each of these ten features, the degree of disturbance shown was assessed at four levels: $0=$ No significant impact, $1=$ Low impact i.e. impact may not be discernible to layman unless observed carefully, $2=$ Moderate impact i.e. impact visible but not threatening to the environmental element, $3=$ High impact i.e. threatening the very existence of a species; high level of 
habitat degradation. A Cumulative Disturbance Index (CDI) was calculated for the locality by adding the ten scores, giving a maximum CDI of 30 .

\section{Results}

\section{Size}

The area of sacred groves ranged from few square meters to several hectares. Out of 66 sacred groves surveyed, nearly $52 \%$ of the groves have an area less than 0.5 ha. Sacred groves between $0.5-2.0$ ha contributed to $32 \%$ of the total. Only two groves (3\%) have a size greater than 5 ha, of which one is owned by the forest department and the other by the temple trust. Figure 2 depicts the representative sacred groves from the study area. The majority of the groves are located within the boundary of the village or in the vicinity of the village. Ninety percent of the groves lie within a distance of $0-2 \mathrm{~km}$ from the village. The farthest sacred groves were those of Nangartas and Karlai which are situated at a distance of nearly $4 \mathrm{~km}$ from the nearest habitation. Groves such as Phakan Rai and Lingachi Rai of Gele Village (Fig. 2.1) were comparatively inaccessible and this has a positive impact concerning the anthropogenic pressures they are facing, with the groves maintained in relatively undisturbed condition.

\section{Surrounding land use}

The land surrounding the majority of the sacred groves (35\%) is primarily used for agriculture and habitation (Fig. 2.2). This land use was characteristic of those sacred groves that are situated on the Western Ghats crest line, whereas the groves that are situated at the foothills of the Western Ghats (15\%) has horticulture and agriculture as surrounding land use. Only $15 \%$ of the groves are in a continuum with the natural vegetation cover or forest (Fig. 2.3). It is interesting to note that $13 \%$ of the groves have forest, agriculture, and/or horticulture as surrounding land use indicating probable intrusion or expansion of this form of cultivation practices into the forest. Paddy is the main crop of the area, while cashew-nut (Anacardium occidentale), coconut (Cocos nucifera), and mango (Mangifera indica) orchards, and banana (Musa spp.) plantations are major horticultural crops of the region. The area under such cultivation is slowly expanding and this can be viewed as a future threat both to the forest (cut-clear-cultivate) and sacred groves (shrinkage in size). The planting of exotic varieties (for example, Eucalyptus spp.) inside and outside the sacred groves was also observed in some instances and is a looming threat.

Apart from providing cultural services to the local people, sacred groves also provide other ecosystem resources, of which water being an important one. Nearly $35 \%$ of the groves have either perennial or seasonal streams associated with them. The Hiranyakeshi River finds its origin in the Hiranyakeshi sacred grove, while a perennial spring that supplies water to nearby villages originates in the Karlai sacred grove. A perennial water hole which is the only source of 

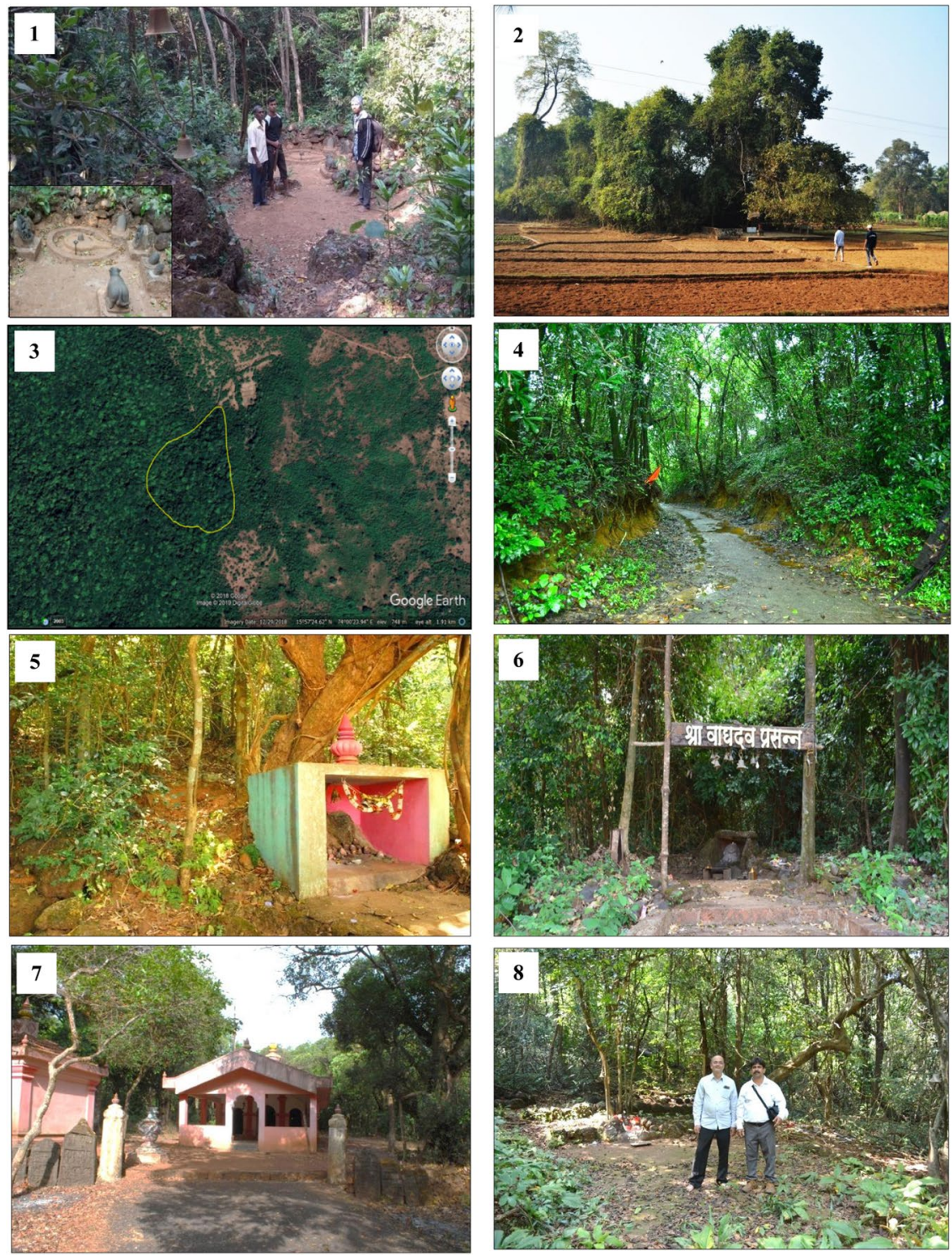

Fig. 2 Representative Sacred Groves from the Study Area

water for wildlife during summer finds its origin in the Phakan Rai grove situated in the reserve forests. This highlights the significance and role of these unique landscape elements in providing ecosystem services to the local people. 


\section{Ownership}

Understanding ownership of the groves has become an absolute necessity as it provides insights directly and indirectly about the proximate and ultimate drivers that affect the overall area and the status of the groves. The nature of ownership provides insights into (i) the degree and kind of intervention allowed in the grove, (ii) the framing of rules and regulations (as a code of conduct) and norms of behavior, and (iii) punishment of offenders if any. The following pattern of ownership was observed in this study; the largest proportion of sacred groves were owned by village councils (panchayat) (48\%), followed by temple trusts (41\%), the local forest department $(6 \%)$ and individual families $(5 \%)$.

The high percentage of sacred groves owned by temple trusts can be attributed to the formation of Paschim Maharashtra Devsthan Prabodhan Samiti (a body that looks after the management of temples) in the 1960s which brought a few thousand temples and their groves from Western Maharashtra under the jurisdiction of the government (Revenue Department). In the majority of the sacred groves we visited, though the management formally rests with the temple trust or village panchayat, the clan elders (gavkar) play a vital role in the overall decision-making process. Malhotra (1998) identified five hierarchical levels of management of sacred groves in terms of their geographical influence including intra village, village, local, regional and pan Indian levels. It was observed that inhabitants of a village or even different ethnic groups, as well as different castes in multi-ethnic societies have their groves. In the present study, we came across such groves whose ownership and management rest with the Scheduled Caste community. In these groves, all the rituals and festivals, including priestly activities, are performed by people belonging to that particular caste only. Such a pattern of having separate groves seems to be fairly widespread among the tribes of Jharkhand, Chhattisgarh, and Orissa. We also encountered a few sacred groves that are privately owned by families (Fig. 2.4). An interaction with them revealed that these families take pride in preserving these sacred groves. Private ownership of sacred groves adds a different dimension to the overall protection and conservation of these remnant forest patches. In the study area, of the total land area, the land under private ownership with natural vegetation cover is $60-70 \%$ as compared to the area owned by the state forest department (10-15\%). This may be a reason for the low proportion of forest department-owned sacred groves in this study.

\section{Deity}

Despite variation in size, one common feature of all sacred forest groves is their association with gods and goddesses (Chandrakanth et al. 2004), which often results in their protection by local communities on religious or spiritual grounds. Each village normally has one or two sacred groves (devrai or dev-rahati) and they worship their deities in their respective sacred groves. Some of the villages in the study area even have more than four groves. Apart from individual worship, community gatherings, and community worship also take place in these groves. In many cases where a 
temple has not been constructed, gods and goddesses are symbolized in the form of old trees or with the deity resting at the base of a tree (namely Ficus tsiela, Terminalia bellirica) (Fig. 2.5). Of the 66 sacred groves, only two sacred groves are named in connection with wild animals viz. tiger (Panthera tigris) associated with the deity Waghdeo, and the Indian cobra (Naja naja) associated with Nagachi Rai. Many sacred groves in the study area have been used as 'burial' grounds and hence ancestral spirits are also worshipped in these sacred groves. Of the total sacred groves studied, 50\% have iconic images (rock face portrayed in human/animal form), $20 \%$ are aniconic (rock face not portrayed in human/animal form i.e. not forming an image), whereas $26 \%$ were dedicated to spirits (represented in abstract form, existing only in mind, separated from embodiment). In a few incidences, we came across only bells as sites of worship (Fig. 2.5). We observed that of the 66 sacred groves surveyed, $47 \%$ have male deities and $29 \%$ have female deities. Only in one sacred grove (Padlos), did we come across idols of both male and female deities. Chandran (1995) also reported the occurrence of both male (Bhutappa, Jatakappa) and female (Choudamma) deities associated with sacred groves in Karnataka. Gadgil and Vartak (1976) found, among 23 sacred groves in Maharashtra, 15 are associated with goddesses, one with ancestral spirits, one with a male deity, and in three groves local people practice phallic worship.

\section{Cultural services}

The Millennium Ecosystem Assessment (MEA) Framework (2005) identifies the cultural services of the forests/vegetation patches as one of the key "Provisioning Ecosystem Services". The present study assessed environmental concerns by looking at the intrinsic values for visitors and also for sites along with their non-use, use, and spiritual and recreation values for associated villagers and the general public (Table 2). Such cultural services include folklore, taboos, customs, community participation, code of conduct, and norms of behavior.

In India, a rich ecological ethic emphasizing the interconnection of people and the nature was reflected in the various forms of nature worship which permeated across the subcontinent (Deb and Malhotra 2001). Local tribal and Hindu cultures observed restrictions on the use of resource items to specified seasons. For example, no part of the Karam (Adina cordifolia) tree is harvested by the Kora, Santal, Munda, and Bhumij tribes until the Karam festival in August-September. These festivals seem to mark the termination of periods of use-restriction on important resources. It is a common practice to use large number of plants in Hindu ceremonies and rites. Aside from the banana (Musa spp.), betel nut (Areca catechu), and tulsi (Ocimum sanctum), all such plants required for ritual use are found in the wild. The ritual usefulness of certain species necessitated the practice of statutory domestication. For example, Ocimum sanctum is now common on each Hindu homestead. Likewise, in a comprehensive study documenting role of traditional beliefs in Eastern Himalayan tribes of Arunachal Pradesh, Janaki et al. (2020) reported that out of the 15 tribes surveyed, 14 tribes exhibited taboos against the extraction of ungulates and carnivores. It was found that, of the 28 mammals protected by taboos and 


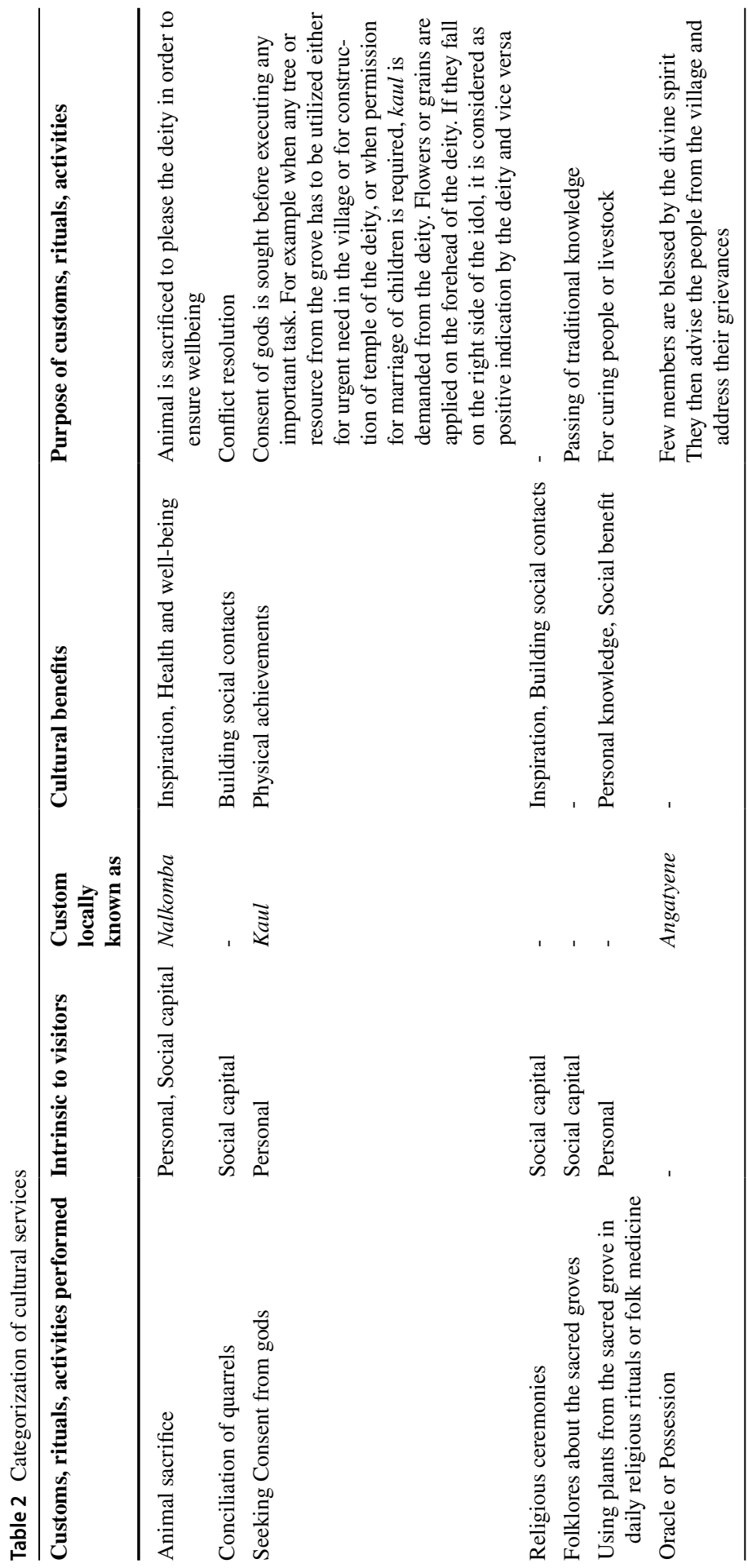


beliefs, 8 were endangered, 13 were vulnerable and 6 were near threatened species as per the IUCN Red List.

Each sacred grove we studied is unique both in terms of biodiversity and the culture associated with it. Rituals that are performed in the sacred groves vary from one to another though some rituals are common. The practice of offering worship using flowers, coconuts, and kumkum (a holy dye used in religious ceremonies in India) to the deity is observed in all the sacred groves. In these rituals, diverse biological species are required. The plant and animal species used include some found within the sacred grove and some from outside the sacred grove as well. The species used might be natural/wild or domesticated. For example, we came across incidences of leaves of the endemic tree Holigarna grahamii used by the local community for worshipping the deity in one of the sacred groves from the district of Raigad. Some individuals of this species, having grown undisturbed in the sacred groves, have become quite hefty. It was found that people from Dhangar, who are cattle breeders, use Syzigium cumini leaves in all their rituals. Similarly, species such as Vateria indica, that is seldom seen in the study area was recorded in the Sateri Devi sacred grove of Choukul Village. The resin extracted from this species is used in all auspicious rituals performed in the sacred grove and there have been deliberate attempts by the local people to propagate the plant and protect this species within the temple premises.

The practice of animal sacrifice was observed in the sacred groves that are associated with the Dhangar community. In some groves, such a practice (especially sacrifice of Wild Boar - Sus scrofa) was found in earlier times, however, this practice doesn't exist today. It is interesting to note that there are sacred groves dedicated to Waghdeo (a tiger deity), and thus tigers are worshipped (Fig. 2.6) and not hunted by the local people.

\section{Common customs and taboos}

Common customs, taboos, and beliefs associated with these sacred groves are reported below. In the majority of the cases, such practices are strictly followed. There is a belief that if a person fails to follow these practices, it will invite the wrath of the spirits:

(i) Sacred forests are home to guardian spirits. These sites have spiritual values which local people believe helped their ancestors to live for many years. (ii) Collection activities (whether for fuel-wood, timber, honey, etc.) are banned from the grove. Even removing a dead log is a taboo. (iii) If timber or any other natural resource is required for the village, there is a common practice of requesting the consent of the appropriate god. Obtaining forest resources without permission may lead to divine punishment for the person or a whole family. (iv) Folk healers (vaidu) obtaining resources from sacred groves were believed to be able to cure any disease and to prevent death. (v) Cattle grazing and hunting are strictly prohibited in these groves. (vi) By and large, there is no restriction on gender and therefore entry of women in the sacred groves is permissible and not considered taboo. However, women are not permitted to enter the sacred grove during their menstrual cycle as 
they are considered to be ritually unclean. (vii) Activities such as smoking, drinking alcohol, urinating, and defecating are banned in the sacred groves.

\section{Sanskritization}

Many gods and goddesses still reside in these groves in a natural condition in the form of aniconic stones or images where they are exposed to the environment. Shelter to these deities, if provided, is in the form of a small, primitive, symbolic temple. One of the key aspects of the process of Sanskritization is the replacing of such temples with large constructions (Fig. 2.7) in the name of rejuvenating the deity. This process, however, has a negative impact on the overall health of the grove as the natural vegetation is cleared to accommodate the new temple. Almost $50 \%$ of the groves from the study area have undergone this process and the concurrent clearing of large trees.

\section{Awareness}

Culture, tradition, and religious beliefs have been the backbone of the sacred grove institution for over centuries. All of these together have protected these forest patches in their natural, healthy state. However, with the rising developmental pressures, this cultural backbone is facing a crisis. We assessed the understanding of the local people about various aspects associated with the grove and depicted them in Fig. 3. It was observed that more than $80 \%$ of the people of all age classes were aware of the presence of the grove. The younger generation which now shows an increasing trend of migration to urban areas has different ideas of celebrating traditional festivals. These non-traditional methods essentially distance the youth from their original culture and rituals related to the sacred groves. Hence a decline in the

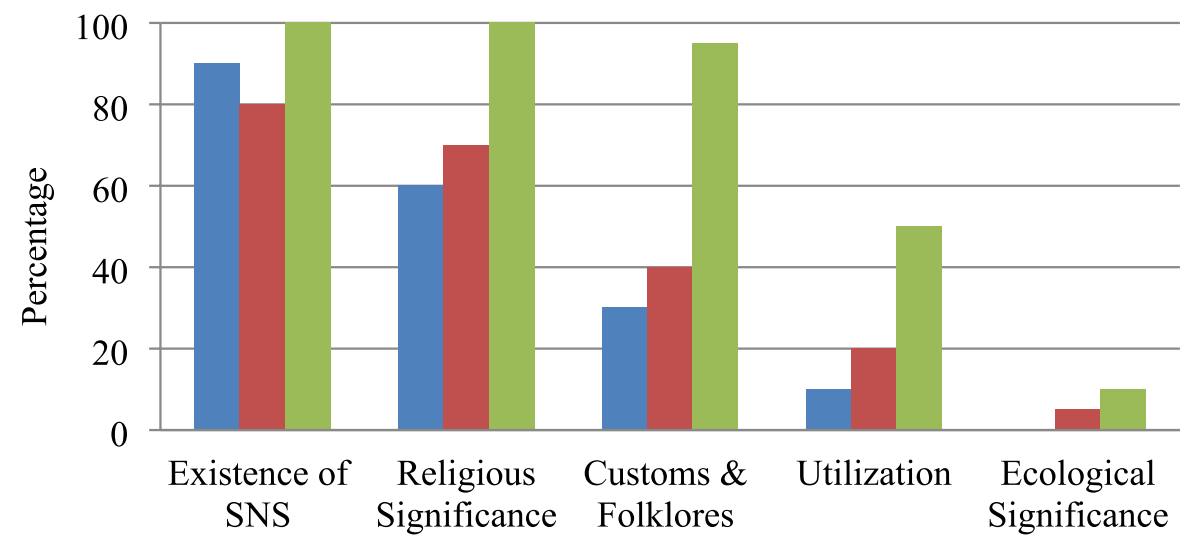

$$
\text { - School Children } \quad \text { Youth } \quad \text { Elders }
$$

Fig. 3 Awareness of Various Dimensions of Sacred Groves, by Age Group 
percentage of awareness of religious significance was observed (60-70\%). The percentage further declined to less than $40 \%$ regarding the knowledge of customs, stories, and anecdotes associated with these groves. The understanding of the utilitarian value of the groves showed a decline across age class with elders having maximum knowledge (nearly 50\%), youth (20\%) and school children (10\%). Awareness regarding the role of groves in protecting threatened and endemic plant and animal species, aquifer recharging, nutrient cycling, pollination, and as a repository of species useful to humans (medicinal or wild edible) is lacking to an alarming extent $(<10 \%)$ in both older and younger generations. It was noted that beliefs or responses such for a feeling of awe or fear of the deity and that it is possible to invite the wrath of spirits are rapidly eroding, reflecting a cultural shift which poses a great threat to the existence of the groves; not surprisingly, their number is decreasing sharply.

\section{Discussion}

In many states across India such as Karnataka, Assam, and Meghalaya, sacred forest groves vary widely in their size, ranging from small fragments of forest $(<1 \mathrm{ha})$, to more extensive (spanning $>100$ ha) (Malhotra et al. 2000; Bhagwat et al. 2013; Acharya and Ormsby 2017). In the current study, we mainly came across small-sized groves ( $<1$ ha). Only one grove was large and exceeded an area of 10 ha. Sacred groves are diminishing at an alarming rate owing to activities such as road construction, mining, and dam construction, as well as the increasing monetary incentive for their clearing for commercial use. These factors are making it increasingly difficult to sustain these systems in the long term. Only a very small proportion of the sacred groves in this study (5\%) were found to be undisturbed, while an exceedingly high proportion, $95 \%$, were either moderately disturbed $(60 \%)$ or highly disturbed $(35 \%)$. In terms of determinants and threats to the preservation of groves, a few overarching themes emerged.

\section{Grove ownership}

Grove ownership is significantly related to the protection given to the grove. In the case of privately-owned sacred groves, it was observed that it is comparatively easy to convince an individual of the need to protect to the grove, as the decision-maker is a specific person or a family. Conversely, this factor also poses a threat, as degradation or destruction may happen at a faster rate as the individual is the sole decision-maker. In the case of community- or temple-trust-owned sacred groves, decisions about protection and/or degradation are made through a collective decision-making process and as a result, both protection and destruction can happen at a slower rate. Regarding grove specific practices, Malhotra and Das (1997) observed the taboo preventing the entry of women into the sacred groves among the tribes of southwest Bengal and those of the Koraput district of Orissa. We found that this taboo is eroding these days with increasing awareness of gender equality; however, in some sacred groves (such as Aros-Dadoba 
- Fig. 2.8) this practice is still being followed very strictly. In the majority of the sacred groves, festivals and ritual activities are performed and the communities have their own yearly festival calendar. Groves are also found to be sites of conflict resolution for the villagers, allowing for the maintenance of social harmony within communities. Many groves we observed are situated at the boundaries of the two adjacent villages. These often are areas that are some distance away from the villages and therefore no festivals are celebrated in such groves. These groves often don't have a temple where people can meet for social gatherings and perform rituals collectively. Such groves are mainly used as places of individual worship.

\section{The loss of traditional belief systems}

A gradual loss of cultural beliefs is considered a major threat to sacred groves. Detailed data collected about the past and the present state of belief systems revealed that although most traditional customs were practiced even today, some had undergone modification over the years. Alterations to many of the customs and rules observed were also reported. Initially, many communities with sacred groves regularly practiced animal sacrifice. But now, in many instances, animal sacrifice has been replaced by offerings like coconuts, fruit, flowers, kumkum, etc. One of the primary reasons given for the younger generation's decreasing faith in the sacred grove institution was their decreased association with the grove. In many of the villages we came across, it was noted that village youths do not reside in the village, instead they migrate to nearby cities or townships. Having been exposed to the modern world in the cities, they tend to look at the sacred groves as being related to superstitious practices. As a result, they no longer believe in the potential to invoke the wrath of the spirits. The activities that were previously banned in the grove such as hunting have been observed in some instances. We did come across traps for small mammals such as blacknaped hare (Lepus nigricollis) and ground-dwelling birds like Grey jungle fowl (Gallus sonneratii) in some of the groves.

\section{Increasing human encroachment}

Our findings align with other investigations into instances of human encroachment into sacred groves; for instance, a comprehensive overview of sacred groves in 33 different countries found human encroachment to be a major threat (Bhagwat and Rutte 2006). Our study suggests that surrounding land use and the construction of large temples are frequently responsible for the degradation of the groves; consequently, some sacred groves have decreased in the area owing to ingress by agriculture and/or horticulture. Though we did not come across a clear shrinkage in size or the total disappearance of the groves as a result of disturbance, it was observed that the groves are becoming fragmented, degraded, and opened up by loss of canopy cover owing to temple construction and/or construction of roads that pass through the groves. A damaging consequence of this 
fragmentation is that it allows exotic weeds that are heliophilic to rapidly colonize degraded land (e.g. Chromolaena odorata). Further observation of human encroachment includes cattle grazing and the collection of firewood in the sacred groves that are in the vicinity of some villages. In all observed cases, we found that the community is the major decision-maker, with community institutions having the ability to enforce regulations. While the use of groves for livelihood generation were found to be largely absent, we noted the practice of auctioning available bio-resources (e.g. Acacia concinna) from some of these groves, while folk-healers do collect medicinally important plant species for local use. It is important to note that any protection of biodiversity occurring in these groves is not due to the realization of the vital ecosystem services they provide, but rather, is a byproduct of cultural and religious mores that has been stringently observed, up until this point. It is therefore imperative that the scientific and ecological values of these critical ecosystems are explained to the people for their long-term sustenance.

\section{Conclusion}

In India, where considerable biodiversity exists in the landscapes outside the formal Protected Area network, areas such as sacred groves are actively managed and modified by humans. Though one can identify threats such as road construction, expanding agriculture, and temple construction as proximate drivers of change in these cultural landscapes, ultimate drivers include culturally inappropriate modernization, and the erosion of traditional belief systems coupled with the larger overall forces of development, urbanization, and rampant deforestation. This has a negative impact on cultural knowledge transfer and causes a shift in local knowledge bases. One reason for this is that less time is spent experiencing nature with community elders and local knowledgeable individuals. It has been observed that the privatization of lands and urban migration created a shift away from traditional resource management, often at the cost of biodiversity. This has resulted in the erosion of place-based cultures as people are physically separated from the lands on which their beliefs are centered. Stories, narratives, ceremonies, and rituals all lose their meaning when placed outof context, often leading to cultural collapse (Samson 2003).To address this, Millennium Development Goals (MEA 2005) highlighted the need for an integrated approach to the conservation of biological and cultural diversity as the existence of each is inherently linked with each other. There is also growing agreement that cultural landscapes are worthy of protection (i.e. IUCN Category V protected areas) where the interaction of humans and nature over time has produced a particular set of natural and cultural conditions (Phillips 2002, 2003).

National Biodiversity Strategy Action Plan of India has identified following issues: (i) protection and prevention of extinction of threatened species and (ii) enhancement in the area based on Protected Area designation, as key intervention areas for biodiversity protection. This requires urgent and significant action to reduce the degradation of natural habitats. Sacred groves act as wildlife refuges 
and are known to be repositories of many threatened and endemic species of plants and animals. Maharashtra State Biodiversity Board, a regulatory body under the National Biodiversity Authority has prioritized sacred groves as one of the biodiversity hot-spots in the state that needs immediate attention. Though there is increasing recognition of the fact that people do have their own systems of conservation, sacred groves hardly find any place in forest department working plans at the local level or integrated with formal conservation planning at the regional level.

To address this, local revitalization initiatives are being undertaken under the "Mission Devrai" program by networking with grass root level organizations, community based organizations, and schools to generate awareness about these cultural sites. Such initiatives are also addressing the importance of educating people on the ecological benefits of sacred groves. Ministry of Environment, Forests \& Climate Change (MoEF\&CC, Government of India) partnering with academic institutions and non-governmental organizations launched a network program titled,'All India Coordinated Research Project on Sacred Grove Ecosystem Service Assessment', spreading across 18 states of India.

The information thus generated through such studies can be used effectively by the Biodiversity Management Committee (BMC), now mandatory under the provisions of the Biological Diversity Act (2002). This Act also has a provision for declaration of heritage sites or Community Conserved Areas (CCA). Carefully designed ecotourism initiatives (centered on sacred groves), where culturally appropriate, and traditional health care systems integrated along with careful commercialization of traditional food systems can form a viable example of incentive based conservation approach. Conserving such unique landscape with rich cultural and ecological history involving BMC and other stakeholders such as local communities and the Forest Department will reveal new facets of a participatory conservation model that can be replicated elsewhere. This will not only recognize such informal institutional efforts but also strengthen protection of the sacred groves benefitting both the ecosystem and the cultural values of people.

Acknowledgements The study was a part of the project entitled, 'Inventorization, Mapping and Identification of Biodiversity Rich Sacred Groves from proposed Eco-sensitive Zones of Sawantwadi and Dodamarg taluks of Maharashtra' supported by Maharashtra State Biodiversity Board (MSBB). The support from RANWA and the Principal, Abasaheb Garware College, Pune is duly acknowledged. We also thank Pramod Sawant, Forester, Research Wing (Western Circle); State Forest Department, Kashiram and Shivram Gawde, Kaka Bhise for their cooperation. Assistance in the field by Ganpat Kale, Apoorva Sahasrabudhe, Sahil Pimpale is also acknowledged. Thanks are also due to Aley Joseph Pallickaparambil, Rucha Modak, Sampada Borgaonkar, Yogesh Gokhale and Prof. K. C. Malhotra and departmental colleagues for their inputs.

Authors' contributions AP-Conceptualization, Methodology, Validation, Investigation, Writing- Reviewing and Editing, Visualization, Supervision, Funding acquisition. PG-Methodology, Validation, Formal analysis, Investigation, Data curation, Writing - original draft preparation, Visualization, Design of the work. MM-Investigation. AB - Investigation. The author(s) read and approved the final manuscript.

Authors' information Dr. Ankur Patwardhan is an associate professor and heading Annasaheb Kulkarni Department of Biodiversity at Abasaheb Garware College, Pune, India. He holds a doctorate in Environmental Sciences. His research interests include recovery, including ex-situ and bio prospecting of 
threatened plant taxa from Western Ghats global biodiversity hot-spots. The activities include quantification and mapping of plant resources, besides documenting traditional knowledge and community conservation practices. He also undertakes Ecological Assessments projects and Biodiversity Management Plans. In honorary capacities, he guides research activities at RANWA, an NGO active in the field of biodiversity research and awareness.

Pooja Ghate is a project fellow at RANWA, Pune. She has keen interest in studying seed ecology and plants-animals interactions. She has participated in ecological assessments and environmental awareness drives at various schools.

Monali Mhaskar has completed her Masters' from Biodiversity from University of Pune. She is an awardee of Women Scientist Scheme (WOS-B) of Dept. of Science \& Technology, Govt. of India, She has worked extensively on assessment of provisioning ecosystem services of sacred groves from state of Maharashtra. She is a research associate at RANWA.

Amit Bansude has done his Masters in Forestry from Konkan Krishi Vidyapeeth, Dapoli. His research interests include plant diversity studies and development of mass multiplication protocols of threatened plant species.

Funding The study is supported by Maharashtra State Biodiversity Board.

Availability of data and materials All data generated or analysed during this study are included in this published article and its supplementary files.

\section{Declarations}

Ethics approval and consent to participate 'Not Applicable'.

Consent for publication Not applicable.

Competing interests The authors declare that they have no competing interests.

Open Access This article is licensed under a Creative Commons Attribution 4.0 International License, which permits use, sharing, adaptation, distribution and reproduction in any medium or format, as long as you give appropriate credit to the original author(s) and the source, provide a link to the Creative Commons licence, and indicate if changes were made. The images or other third party material in this article are included in the article's Creative Commons licence, unless indicated otherwise in a credit line to the material. If material is not included in the article's Creative Commons licence and your intended use is not permitted by statutory regulation or exceeds the permitted use, you will need to obtain permission directly from the copyright holder. To view a copy of this licence, visit http://creativecommons.org/licen ses/by/4.0/.

\section{References}

Acharya, Amitangshu, and Alison Ormsby. 2017. The cultural politics of sacred groves: A case study of Devithans in Sikkim, India. Conservation and Society 15 (2): 232-242. https://doi.org/10.4103/cs. cs_14_29.

Berkes, Fikret. 2009. Community conserved areas: Policy issues in historic and contemporary context. Conservation Letters 2: 19-24. https://doi.org/10.1111/j.1755-263X.2008.00040.x.

Bhagwat, Shonil, and Claudia Rutte. 2006. Sacred groves: Potential for biodiversity management. The Ecological Society of America 4 (10): 519-524.

Bhagwat, Shonil, Cheppudira Kushalappa, Paul Williams, and Nick Brown. 2005. A landscape approach to biodiversity conservation of sacred groves in the Western Ghats of India. Conservation Biology 19 (6): 1853-1862. https://doi.org/10.1111/j.1523-1739.2005.00248.x. 
Bhagwat, Shonil, Sandra Nogue, and Katherine Willis. 2013. Cultural drivers of reforestation in tropical forest groves. Forest Ecology and Management 329: 393-400. https://doi.org/10.1016/j.foreco.2013. 11.017.

Burman, Roy. 1996. A comparison of sacred groves among the Mahadeo-Kolis and Kunbis of Maharashtra. Indian Anthropologist 26: 37-45.

Cardelus, Catherine, Peter Scull, Alemayehu Eshete, Carrie Woods, Peter Klepeis, Eliza Kent, and Izabela Orlowska. 2017. Shadow conservation and the persistence of sacred church forests in northern Ethiopia. Biotropica 0 (0): 1-8.

Chakraborty, Parikshit. 2019. Socio-cultural aspects of sacred groves: The study in a Santal village. EAS Journal of Humanities and Cultural Studies 1 (1): 50-53 https://www.researchgate.net/publication/ 331311469 .

Chandrakanth, M.G., Mahadev Bhat, and M.S. Accavva. 2004. Socio-economic changes and sacred groves in South India: Protecting a community-based resource management institution. Natural Resources Forum 28: 102-111.

Chandran, Subash. 1995. Peasant perception of Bhutas: Uttara Kannada. In Prakrti: The integral vision, primal elements: The oral tradition, vol. 1, ed. Kapila Vatsyayan and Baidyanath Saraswati, 151166. New Delhi: Indira Gandhi National Centre for the Arts.

Chandran, Subash, and Donald Hughes. 1997. The sacred groves of South India: Ecology, traditional communities and religious change. Social Compass 44 (3): 413-427. https://doi.org/10.1177/00377 6897044003008.

Critical Ecosystem Partnership Fund. 2007. Ecosystem profile: Western Ghats and Sri Lanka biodiversity hotspot- Western Ghats Region. https://www.cepf.net/sites/default/files/western-ghats-ecosystemprofile-english.pdf. Accessed 5 Apr 2020.

Deb, Debal, and Kailash Malhotra. 2001. Conservation ethos in local traditions: The West Bengal heritage. Society and Natural Resources 14 (8): 711-724. https://doi.org/10.1080/0894192011 8542 .

Gadgil, Madhav, and V.D. Vartak. 1975. Sacred groves of India: A plea for continued conservation. Journal of Bombay Natural History Society 72: 314-320.

Gadgil, Madhav, and V.D. Vartak. 1976. Sacred groves in Western Ghats in India. Economic Botany 30: $152-160$.

Gadgil, Madhav, and V.D. Vartak. 1981. Sacred groves in Maharashtra: An inventory. In Glimpses of Indian ethnobotany, ed. S.K. Jam, 279-294. New Delhi: Oxford and BH Publishers. https://doi.org/ 10.3372/wi.45.45209.

Hall, Jonathan. 2011. Ecological dynamics of vultures, blackbuck antelope, Khejeri trees, and the Bishnoi people in Western Rajasthan, India. Dissertation, Graduate Program in Evolution, Ecology and Organismal Biology, the Ohio State University. https://etd.ohiolink.edu/!etd.send_file?accession= osu1313171819\&disposition=inline. Accessed 5 Apr 2020.

Janaki, M., Rohan Pandit, and Rishi Sharma. 2020. The role of traditional belief systems in conserving biological diversity in the Eastern Himalaya Eco-region of India. Human Dimensions of Wildlife. https://doi.org/10.1080/10871209.2020.1781982.

Loki, Viktor, Jacint Tokolyi, Kristof Suveges, Adam Lovas-Kiss, Kaan Hurkan, Gabor Srmko, and Attila Molnar. 2015. The orchid flora of Turkish graveyards: A comprehensive field survey. Willdenowia 45 (2): 231-243. https://doi.org/10.3372/wi.45.45209.

Malhotra, Kailash. 1998. Anthropological dimensions of sacred groves in India: An overview. In Conserving the sacred for biodiversity management, ed. P.S. Ramakrishnan, K.G. Saxena, and U.M. Chandrashekara, 423-438. New Delhi: Oxford and IBH Publishing Co.

Malhotra, Kailash, Yogesh Gokhale, Sudipto Chatterjee, and Sanjeev Srivastava. 2000. Cultural and ecological dimensions of sacred groves in India: An overview. Indira Gandhi Rashtriya Manav Sangrahalaya: Bhopal.

Malhotra, Kailash, and Das K. 1997. Interface between Faunal biodiversity and cultural heritage in southwest Bengal in India. In Bioethics in Asia, ed. N. Fujiki, and R. J. Macer, Eubois Ethics Institute Japan, 346-51.

Millennium Ecosystem Assessment. 2005. Ecosystems and human well-being: Biodiversity synthesis. Washington, D.C: World Resources Institute.

Naganso, T.B., R. Kyerematen, and D. Obeng-Ofori. 2012. Review of biodiversity in sacred groves in Ghana and implications on conservation. Current Trends in Ecology 3: 1-10. 
Ormsby, Alison, and Shonil Bhagwat. 2010. Sacred forests of India: A strong tradition of communitybased natural resource management. Environmental Conservation 37 (3): 320-326. https://doi.org/ 10.1017/S0376892910000561.

Phillips, Adrian. 2002. Management guidelines for IUCN category V protected areas: Protected landscapes and seascapes, 122. Cambridge and Cardiff: IUCN and Gland, Switzerland, UK.

Phillips, Adrian. 2003. Turning ideas on their head: The new paradigm for protected areas. The George Wright Forum 20 (2): 8-32.

Samson, Colin. 2003. A way of life that does not exist: Canada and the extinguishment of the Innu. Verso. Original from the University of Michigan.

Tadwalkar, Medhavi, Amruta Joglekar, Monali Mhaskar, Radhika Kanade, Bhanudas Chavan, Aparna Watve, K.N. Gaaneshaiah, and Ankur Patwardhan. 2012. Dispersal modes of woody species from the northern Western Ghats, India. Tropical Ecology 53 (1): 53-67.

World Wildlife Fund (WWF) (Content Partner). 2007. North Western Ghats montane rain forests. In Encyclopedia of Earth, environmental information coalition, ed. C.J. Cleveland. Washington, D.C: National Council for Science and the Environment.

\section{Comments}

Publisher's Note Springer Nature remains neutral with regard to jurisdictional claims in published maps and institutional affiliations. 